\title{
Mechanical and structural properties of titanium dioxide deposited by innovative magnetron sputtering process
}

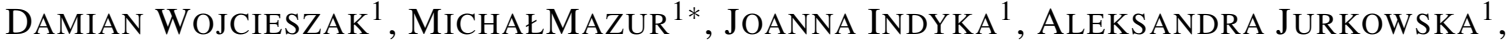 \\ MaŁgorzata KalisZ ${ }^{2}$, Piotr Domanowski ${ }^{3}$, DANUTA KACZMAREK ${ }^{1}$, \\ JAROSŁAW DOMARADZKI ${ }^{1}$ \\ ${ }^{1}$ Faculty of Microsystem Electronics and Photonics, Wroclaw University of Technology, Janiszewskiego 11/17, \\ 50-372 Wroclaw, Poland \\ ${ }^{2}$ Centre for Material Testing and Mechatronics, Motor Transport Institute, Jagiellonska 80, 03-301 Warsaw, Poland \\ ${ }^{3}$ Faculty of Mechanical Engineering, University of Technology and Life Sciences in Bydgoszcz, Kaliskiego 7 , \\ 85-796 Bydgoszcz, Poland
}

\begin{abstract}
Titanium dioxide thin films were prepared using two types of magnetron sputtering processes: conventional and with modulated plasma. The films were deposited on $\mathrm{SiO}_{2}$ and $\mathrm{Si}$ substrates. X-ray diffraction measurements of prepared coatings revealed that the films prepared using both methods were nanocrystalline. However, the coatings deposited using conventional magnetron sputtering had anatase structure, while application of sputtering with modulated plasma made possible to obtain films with rutile phase. Investigations performed with the aid of scanning electron microscope showed significant difference in the surface morphology as well as the microstructure at the thin film cross-sections. The mechanical properties of the obtained coatings were determined on the basis of nanoindentation and abrasion resistance tests. The hardness was much higher for the films with the rutile structure, while the scratch resistance was similar in both cases. Optical properties were evaluated on the basis of transmittance measurements and showed that both coatings were well transparent in a visible wavelength range. Refractive index and extinction coefficient were higher for $\mathrm{TiO}_{2}$ with rutile structure.
\end{abstract}

Keywords: plasma modulated magnetron sputtering; titanium dioxide; hardness; scratch resistance; optical and structural properties

(C) Wroclaw University of Technology.

\section{Introduction}

Determination of various properties of oxide materials and their possible application in optical coatings is nowadays a significant area of research. The most important properties of optical coatings are high transparency, low absorption and appropriate index of refraction. Knowledge of these parameters enables designing of different types of optical coatings, such as antireflective, dielectric mirrors, filters, and so forth. Besides the optical function, another role of coatings is substrate protection from various external hazards. One of the most often applied protective coatings are the wear resistant or so called hard coatings used for protection of different tools. For this aim the coating should

*E-mail: michal.mazur@pwr.edu.pl be characterized by increased mechanical performance from which the most important are the hardness, resistance to scratch damage and proper elasticity. Although many reports about different hard coatings can be found in the subject literature, rare examples are devoted to oxides designated to optical coatings. Moreover, new applications and demands of the customers caused increasing interest for coatings that besides their primary role could also combine additional functionality. Such coatings could be widely used in many fields of science and technology. This concerns the functional optical coatings having additional properties, e.g. increased hardness or resistance to abrasion.

Increased hardness of the material is strongly correlated to density of thin film. The hardness is, therefore, dependent not only on the material type but also on its crystalline structure and 
crystallites size. Optical coatings are usually prepared by application of physical vapor deposition methods, such as evaporation or sputtering. The density of a thin film prepared in such processes depends on the energy of particles reaching the substrates at the place of thin film formation. For example, the energy of particles during thermal evaporation processes is as low as $0.1 \mathrm{eV}$. That causes that prepared thin films are of poor quality with porous-void structure of low density, therefore, poor mechanical properties. For the sake of densification of the thin film, i.e. to receive nanocrystalline structure, usually the energy of particles condensing at the substrate over $100 \mathrm{eV}$ is required [1]. There are several ways for increasing the total energy in vacuum deposition processes. The simplest one is introduction of additional substrate heating, while another is an application of substrate electrical bias that allows attraction of charged ions with increased kinetic energy to the substrate. Another way is decreasing the vacuum pressure what in turn decreases number of collisions of material particles being deposited with residual gases. One of the most effective methods for increasing the condensation energy and assist the thin film densification is application of additional ion source. Usually, heavy neutral ions, such as $\mathrm{Ar}^{+}$, are applied and their high kinetic energy is transferred by striking the particles evaporated from the source and by impinging the substrate. However, too high energy causes that neutral ions might be implanted into the growing thin film that results in the increase of structural defects or even re-sputtering effect can occur. Therefore, the energy of assisted ions, which is also dependent on the kind of the material being deposited, should be selected with care [1]. In the recent years, particularly important have been high energy methods. These include high energy magnetron sputtering methods, e.g. HPPMS (High Power Pulse Magnetron Sputtering) and HERMS method (High Energy Reactive Magnetron Sputtering) [2-6].

Modification of the deposition process parameters enables also forming different crystal structures of the films, which has an effect on the crystallites size. Due to the specifically selected parameters of the manufacturing process it is possible to obtain materials with nanocrystalline structure [7-9]. The hardness of the thin films is usually many times smaller than that of the bulk. However, it was found that for thin films with dense structure the hardness is higher, and for nanomaterials it is possible to achieve the hardness even greater as compared to the bulk [10]. This is because the hardness of the material increases when the grain size decreases with the maximum in the nanometer range (Hall-Petch effect) [10]. Results of the research presented in the subject literature show that oxide materials, which are composed from crystallites of single nanometers in size, exhibit completely different properties than the bulk material of the same chemical composition.

In case of transparent oxides applied in various optical coatings the most often used materials for preparation of optical coatings are $\mathrm{SiO}_{2}$, $\mathrm{Al}_{2} \mathrm{O}_{3}, \mathrm{Nb}_{2} \mathrm{O}_{5}, \mathrm{Ta}_{2} \mathrm{O}_{5}, \mathrm{TiO}_{2}, \mathrm{HfO}_{2} . \mathrm{SiO}_{2}$ is a low index material $(\mathrm{n}=1.46), \mathrm{Al}_{2} \mathrm{O}_{3}, \mathrm{Nb}_{2} \mathrm{O}_{5}$, $\mathrm{Ta}_{2} \mathrm{O}_{5}$, are materials with moderate value of refraction index $(n=1.7 \div 2.1)$, whereas $\mathrm{TiO}_{2}$ and $\mathrm{HfO}_{2}$ are characterized by high index of refraction $(n=2.2 \div 2.6)$.

One of the materials, characterized by high transparency, wide band gap and high electrical resistivity at room temperature is titanium dioxide. Moreover, $\mathrm{TiO}_{2}$ is non-toxic and exhibits good chemical, thermal and mechanical stability. In view of its properties, $\mathrm{TiO}_{2}$ based thin films have wide range of applications. Anatase and rutile phases of tetragonal structure are the most important polymorphs of $\mathrm{TiO}_{2}$ [11]. Titania thin films can be prepared by various physical vapor deposition techniques, e.g. evaporation [12, 13], reactive radiofrequency magnetron sputtering [14-17], reactive pulse magnetron sputtering [18], high power impulse magnetron sputtering $[19,20]$, arc deposition [21] or laser deposition [22]. In the literature several reports can be found regarding the hardness of titanium dioxide thin films. Depending on the preparation method of undoped $\mathrm{TiO}_{2}$ its hardness is in the range from 2 to $13 \mathrm{GPa}$ [23-32].

The following study reveals the influence of various magnetron sputtering processes on 
microstructure, optical and mechanical properties of titanium dioxide thin films.

\section{Experimental}

For the deposition of thin films an own invented multitarget apparatus for magnetron sputtering with an innovative system of targets power control has been applied. The control system of this apparatus is protected by the patent application [33]. Each magnetron is independently powered by its individual supplier (DORA Power Systems), controlled by a microprocessor controller, which in turn, is controlled by a computer equipped with an adequate software. Thanks to that, the distribution of the power supplied to each magnetron and their sputtering time can be precisely controlled. The sputtering workstation is equipped with a standard vacuum chamber, pump system (diffusion and rotary pumps), four magnetrons, a stage with possibility of motion in the XYZ directions, Pfeiffer vacuum gauges and a gas flow control system that involves MKS mass-flow controllers.

Two sets of titanium dioxide thin films were deposited using a conventional and a so-called "magnetron sputtering with modulated plasma" system. In the conventional process the continuous flow of oxygen was preserved at $40 \mathrm{sccm}$. Oxygen was used both as working and reactive gas. During the sputtering process the pressure in the vacuum chamber was kept at ca. $2 \mathrm{~Pa}$. The time of thin film deposition was equal to $120 \mathrm{~min}$. In the process with modulated plasma, oxygen was both used as a working and reactive gas. The time of sputtering was twice as long as in case of conventional process. Moreover, the pressure during deposition was significantly lower and equal to ca. $0.2 \mathrm{~Pa}$. The innovation of this process was introduction of oxygen into the vacuum chamber in short (few tens of miliseconds) pulses, controlled by the special gas injection system.

The surface morphology and cross-section of thin films were investigated with the aid of FESEM FEI Nova NanoSEM 230 scanning electron microscope (SEM) with the resolution of $1 \mathrm{~nm}$ and possibility of working in low vacuum.
Structural properties of $\mathrm{TiO}_{2}$ thin films were determined based on the results of the X-ray diffraction (XRD) method. For the measurements, Siemens 5005 powder diffractometer with $\mathrm{CoK} \alpha \mathrm{X}$-ray $(\lambda=1.78897 \AA)$ was used. The correction for the broadening of the XRD instrument was taken into account and the crystallite sizes were calculated using Scherrer's equation [34].

The nanoindentation technique was used to determine hardness of prepared thin films. Hardness was assessed from the experimental loaddisplacement curves obtained from an indentation experiment using Oliver and Pharr method [35, 36]. Measurements of mechanical properties of prepared coating were performed with a CSM Instruments nanoindenter equipped with a diamond Vickers indenter. In case of analysis of mechanical properties of thin films using nanoindentation technique it is important to recognize the influence of the substrate on the measurement results. The "10 \% principle" [37] is commonly used to minimize the substrate impact: the nanoindentation depth should be less than $10 \%$ of the measured layer thickness. However, this principle cannot be applied for a thin film, whose thickness is often lower than $600 \mathrm{~nm}$, as it would require less than $60 \mathrm{~nm}$ nanoindentation depth. The measurements at a depth less than $80 \mathrm{~nm}$ are characterized by significant errors caused by inaccuracy of determining the area of indentation. Therefore, it is necessary to apply methods of analysis, interpretation and approximation of the results in order to obtain real values of mechanical properties of thin films. Measured hardness of the thin films deposited on substrate can be expressed as a powerlow function of the substrate and the thin film hardness, the depth of nanoindentation and the thickness of thin film [38]:

$$
H=H_{S}\left(\frac{H_{f}}{H_{S}}\right)^{M}
$$

where $\mathrm{H}_{\mathrm{s}}$ - hardness of substrate, $\mathrm{H}_{\mathrm{f}}$ - hardness of thin film, $\mathrm{M}$ - dimensionless spatial function defined by [38]:

$$
M=\frac{1}{1+A\left(\frac{h}{d}\right)^{B}}
$$


where A, B - adjustable coefficients, $\mathrm{h}$ - maximum intender displacement, $\mathrm{d}-$ thickness of thin film.

Equation 1 must fulfil essential boundary conditions: when indentation depth approaches to zero (small indentation displacements), the measured hardness tends to thin film hardness, whereas when indentation depth approaches the thin film thickness, the measured hardness tends to the value of substrate hardness. Nanoindentation measurements were analyzed using the finite element method (FEM) [39-41].

Abrasion resistance of the deposited thin films was investigated using the Summers Optical's Lens Coating Hardness Test Kit. For the purpose of scratch resistance examination, steel wool test was carried out, which consisted of rubbing the surface of $\mathrm{TiO}_{2}$ coatings with a 0 grade steel wool pad using a load of $1.0 \mathrm{~N}$. The steel wool pad was pressed to the surface of the coating at a selected force and was caused to move across the surface for $75 \mathrm{cy}$ cles. Surfaces were examined for scratch resistance by optical microscope and profilometer.

Optical properties were evaluated on the basis of transmittance measurements. The experimental system consisted of an Ocean Optics QE 65000 spectrophotometer and a coupled deuterium-halogen light source. Based on experimental results, such parameters as cut-off wavelength, real and imaginary parts of refractive index were determined. The analysis was performed using FTG FilmStar software.

\section{Results}

Results of SEM investigations revealed that the thin films prepared by conventional magnetron sputtering process were smooth and their surface consisted of visible grains (Fig. 1a). The crosssection image showed fibrous-columnar structure with elongated crystallites. However, SEM investigations of $\mathrm{TiO}_{2}$ deposited by sputtering with modulated plasma showed that the thin film surface was not as homogenous as for the coating prepared by conventional method. Some islands were visible on the surface and according to the cross-section image they had pyramidal shape (Fig. 1b). Based on the cross-section image the densely packed columnar structure with fine grains can be noticed.
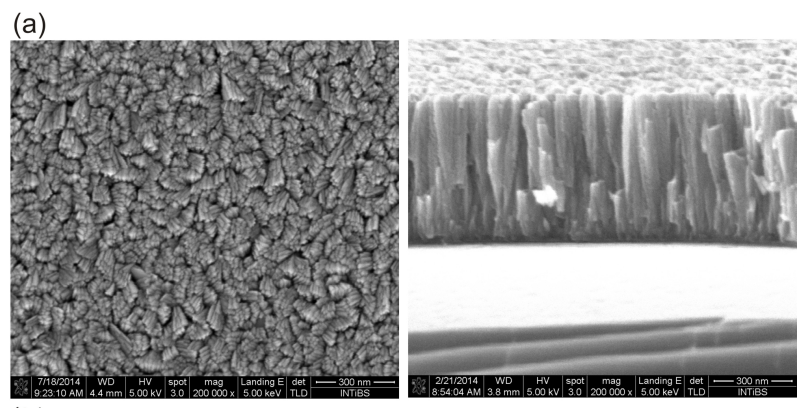

(b)
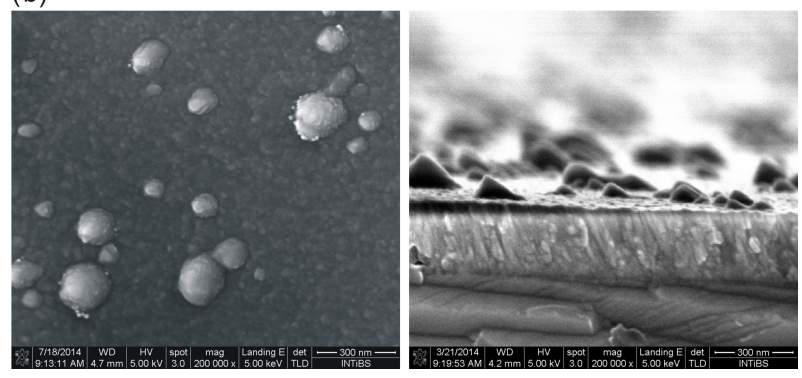

Fig. 1. SEM images of the surface (left side) and cross section (right side) of $\mathrm{TiO}_{2}$ thin films deposited by (a) conventional and (b) modulated plasma magnetron sputtering processes.

XRD measurement results (Fig. 2) showed that titania thin films deposited by the conventional magnetron sputtering process had nannocrystalline anatase phase consisted of ( $\left.\begin{array}{lll}1 & 0 & 1\end{array}\right)$ and (2 000$)$ planes with crystallites size of ca. $26 \mathrm{~nm}$. The diffraction peaks were intense, indicating that these coatings were well crystallized. Taking into consideration the cross-section SEM image (Fig. 1a) one can conclude that these thin films had pseudo-columnar fibrous microstructure.

In case of $\mathrm{TiO}_{2}$ thin films deposited by magnetron sputtering with modulated plasma, the characteristic XRD pattern for the (lllll 110$)$ and $\left(\begin{array}{lll}1 & 0 & 1\end{array}\right)$ rutile crystallographic planes was obtained. However, the pattern was broadened, had very low intensity and, taking into consideration that signal-tonoise ratio $(\mathrm{S} / \mathrm{N})$ was rather poor, the determination of crystallites dimensions could be miscalculated. Therefore, at the sensitivity level of XRD method it can be assumed that these coatings were nanocrystalline and consisted of very small rutile crystallites of ca. $3 \mathrm{~nm}$. Such broadening of the XRD pattern 
(a)

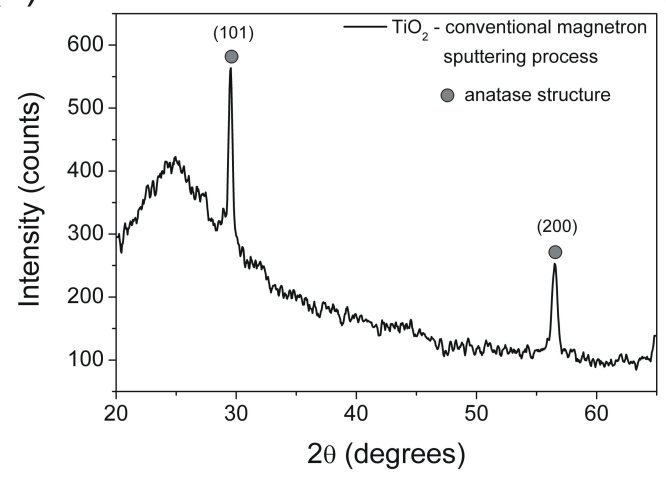

(b)

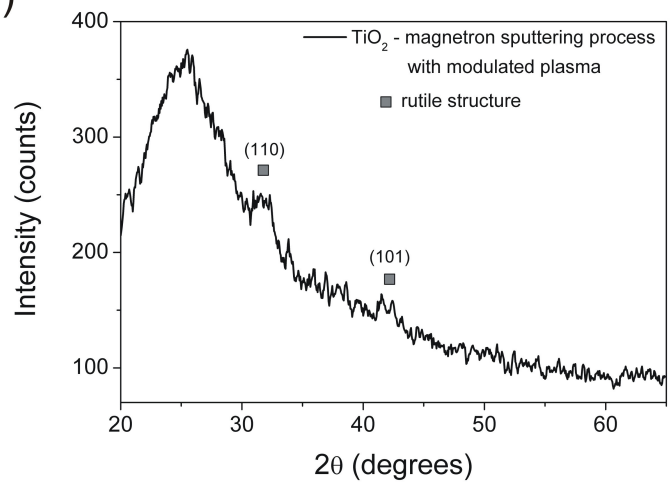

Fig. 2. XRD measurements results of $\mathrm{TiO}_{2}$ deposited by (a) conventional and (b) modulated plasma magnetron sputtering processes $[42,43]$.

can also indicate that large amount of amorphous phase occurred in these coatings.

$\mathrm{TiO}_{2}$ thin films were deposited on amorphous $\mathrm{SiO}_{2}$, whose hardness was equal to $10 \mathrm{GPa}$ according to the nanoindentation measurements. The load-depth curves of prepared thin films for the $10 \mathrm{mN}$ indentation force are shown in Fig. 3. The lower indentation depth obtained for the sample deposited by magnetron sputtering with modulated plasma process indicates that this thin film has higher hardness than the one deposited in a conventional process.

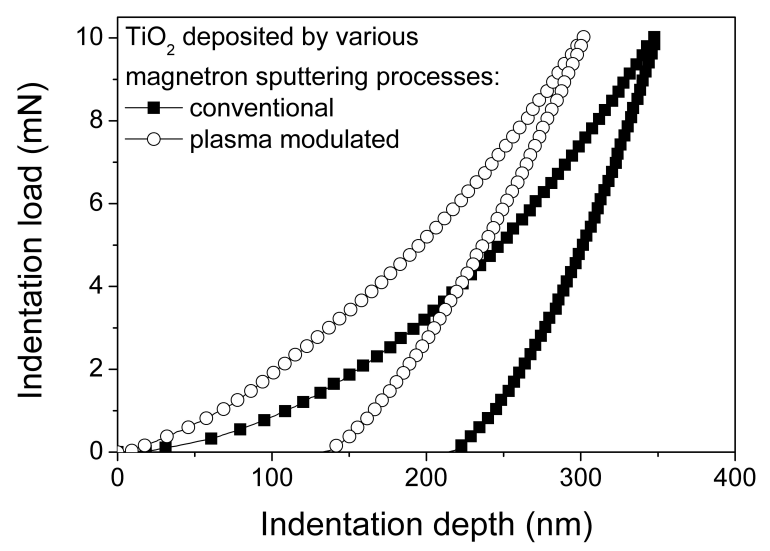

Fig. 3. Indentation load-depth curves of $\mathrm{TiO}_{2}$ thin films deposited by various magnetron sputtering processes.

Titania with anatase structure consisting of elongated crystallites in the pseudo-columnar fibrous structure exhibited much lower hardness as-compared to the $\mathrm{TiO}_{2}$ films with densely packed, fine crystalline rutile structure. Thin films of rutile structure deposited by plasma modulated magnetron sputtering had the hardness equal to ca. 16.1 GPa (Fig. 4a), which was 3.3-times higher value than for titania with anatase structure obtained by conventional sputtering (Fig. 4b). Tribological properties of deposited titania thin films were determined using steel wool test with selected applied load of $1.0 \mathrm{~N}$. Optical microscopy observations of $\mathrm{TiO}_{2}$-anatase thin films showed that the surface contained a lot of slightly visible scratches (Fig. 5a). On the other hand, the surface of $\mathrm{TiO}_{2}$-rutile layers had only several, but visible scratches. The depth of the scratches was determined using Taylor Hobson profilometer (Fig. 5b). The three dimensional images of the thin films surface after these tests are also presented in Fig. 5. Similarly as in case of optical microscopy measurements, the profilometry investigations revealed that titania with anatase phase had a lot of scratches at the surface, however, they were shallow. Moreover, the investigation of $\mathrm{TiO}_{2}$-rutile coating was confirmed by the measurements performed with an optical microscope and showed that its surface contained only several scratches. The depth of the scratches in both cases was equal to ca. 10 to $12 \mathrm{~nm}$ and these results indicated that they had good adhesion to the substrate and were scratch-resistant.

The transmission spectra of deposited titania thin films are shown in Fig. 6. The transmittance 
(a)

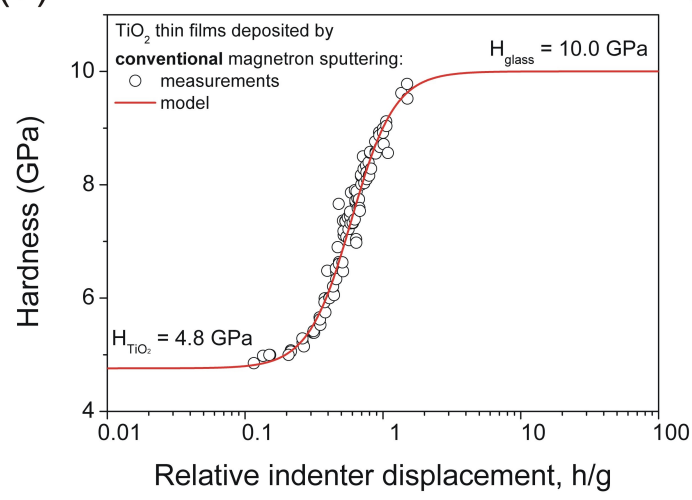

(b)

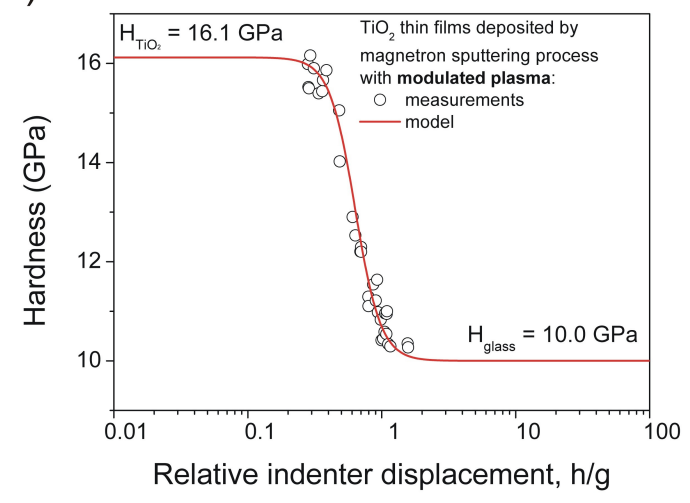

Fig. 4. Results of hardness measurements of $\mathrm{TiO}_{2}$ deposited by (a) conventional and (b) modulated plasma magnetron sputtering processes. The points show nanoindentation measurement results, and solid curves best fits to equations 1 and 2.

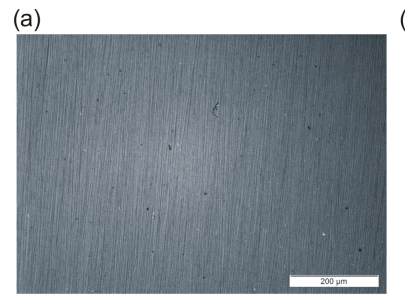

(b)
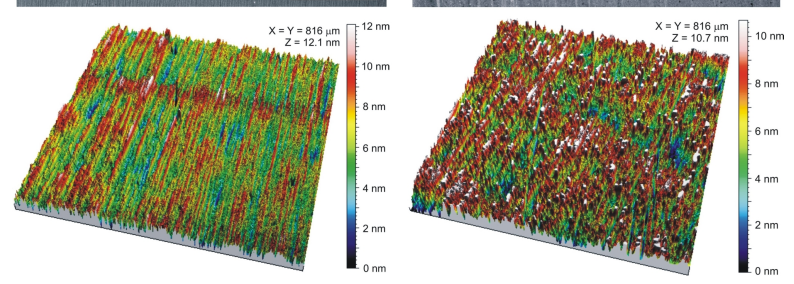

Fig. 5. Optical microscope and profilometer images of thin film surface after scratch tests of $\mathrm{TiO}_{2}$ thin films deposited by (a) conventional and (b) modulated plasma magnetron sputtering.

of the coating prepared by conventional magnetron sputtering was higher than for the ones deposited with modulated plasma. In both cases the transparency was high and equal to ca. 75 to $85 \%$. Although the microstructure of both thin films was completely different, only the slight shift of the fundamental absorption edge was noticed and was equal to $338 \mathrm{~nm}$ and $344 \mathrm{~nm}$ for anatase and rutile coatings, respectively. The presented spectra are the wavelength dependent transmission characteristics in which the interference effects result in visible minima and maxima. The amplitude between these minima and maxima is dependent mostly on the refractive index value, whereas their position vs. the wavelength depends on the thickness of the film. This implies that the anatase coating was much thicker and had significantly lower refractive index than the rutile thin film.

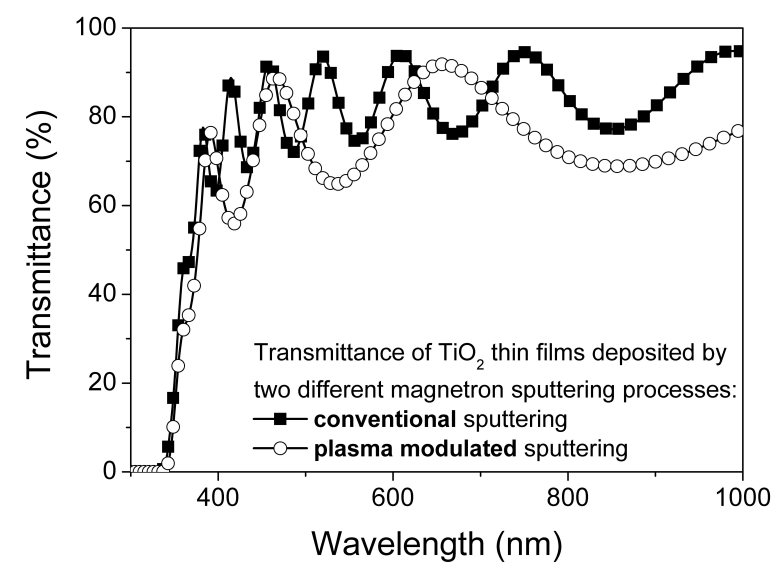

Fig. 6. Comparison of transmittance spectra of $\mathrm{TiO}_{2}$ deposited by different magnetron sputtering processes.

Based on transmittance measurements the analysis of refractive index (n), extinction coefficient (k) and thickness was performed with the aid of FTG FilmStar software using the generalized Cauchy model for materials with $\mathrm{k}$ value higher than 0 . The results are shown in Fig. 7, respectively. As it was assumed, the value of real part of 

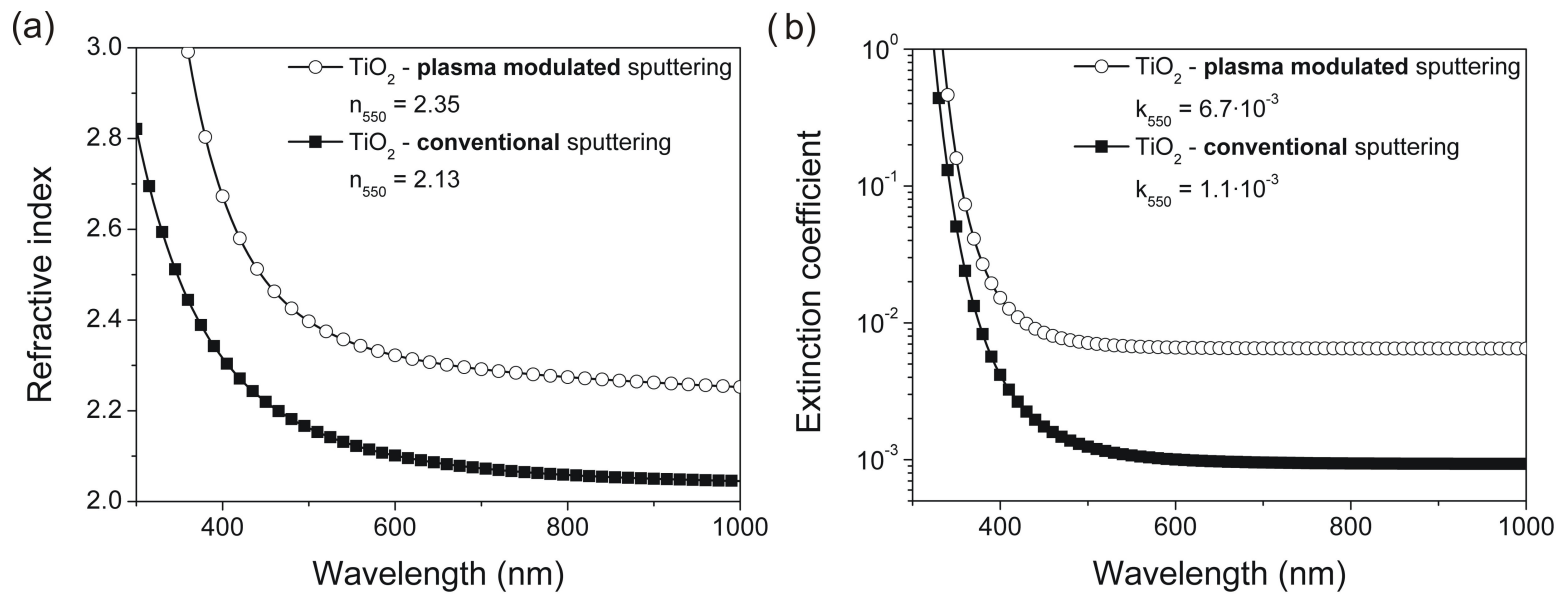

Fig. 7. Refractive index (a) and extinction coefficient (b) spectra of $\mathrm{TiO}_{2}$ deposited by conventional and modulated plasma magnetron sputtering.

refractive index was higher for the coating deposited by sputtering with modulated plasma and was equal to 2.35 at $\lambda=550 \mathrm{~nm}$, while for the thin film prepared by conventional sputtering it was 2.13 at the same wavelength. Also the extinction coefficient of the thin film with rutile phase was higher than that for anatase, which could testify higher absorption of this layer. The thickness of the deposited thin films was ca. $650 \mathrm{~nm}$ for anatase and $290 \mathrm{~nm}$ for rutile. These results were also confirmed by investigations performed with the aid of an optical profilometer.

The comparison of various properties of titanium dioxide deposited by conventional and magnetron sputtering with modulated plasma is shown in Table 1. Although the time of sputtering was two times shorter for the conventional sputtering, the thin film thickness obtained from this process was more than two times higher. This thin film had anatase structure, unlike titania deposited by sputtering with modulated plasma. Also the crystallites size of anatase was much bigger as-compared to the rutile. Additionally, deposition of the rutile coating directly during sputtering process favorably influenced the hardness of this thin film.

\section{Summary}

Investigations of structural properties have shown that $\mathrm{TiO}_{2}$ coatings deposited by conventional magnetron sputtering had anatase structure, while thin films prepared by the process with modulated plasma had rutile phase. The crystallites size were equal to $26 \mathrm{~nm}$ and $3 \mathrm{~nm}$ for the films with anatase and rutile structure, respectively. SEM measurements revealed that the anatase films had fibrous-columnar structure with elongated crystallites, while the rutile ones had densely packed fine columnar structure.

Titanium dioxide thin films deposited by the innovative magnetron sputtering process with modulated plasma had 3.3-times higher hardness as compared to the coating prepared by conventional process. Both thin film coatings were considered as scratch resistant.

The transparency of both $\mathrm{TiO}_{2}$ thin films was similar, while higher refractive index and extinction coefficient were obtained for coatings deposited in the process with modulated plasma. Higher value of refractive index of thin film deposited with modulated plasma were confirmed by higher density of this coating. That could be also the reason that the layer with rutile had higher hardness as compared to that with the anatase.

The obtained thin film coatings with improved hardness, scratch resistance and high transparency could be used in various industry fields. The properties would be beneficial in case of long-term performance of the optical devices. Nanocrystalline rutile titania of precisely specified thickness could be used, e.g. as a high index layer in the construction of antireflective coatings.

The presented results show that there is a huge influence of the type of magnetron sputtering 
Table 1. Comparison of titanium dioxide thin films properties deposited by two different magnetron sputtering processes.

\begin{tabular}{ccc}
\hline Magnetron sputtering process type: & Conventional & With modulated plasma \\
\hline \hline Thin film thickness $(\mathrm{nm})$ & 650 & 290 \\
Structure type & anatase & rutile \\
Crystallite size $(\mathrm{nm})$ & 26 & 3 \\
Hardness $(\mathrm{GPa})$ & 4.8 & 16.1 \\
Refractive index & 2.13 & 2.35 \\
Extinction coefficient & $1.1 \times 10^{-3}$ & $6.7 \times 10^{-3}$ \\
$\lambda_{\text {cut }- \text { off }}(\mathrm{nm})$ & 338 & 344 \\
\hline
\end{tabular}

process on the structure and hardness of $\mathrm{TiO}_{2}$ thin films. In case of the processes it is advisable to use plasma modulation in magnetron sputtering to obtain optical coatings with increased hardness.

\section{Acknowledgements}

This work was co-financed by the NCN as Research Project Number: DEC-2013/09/ST8/00140. The Authors would also like to acknowledge the financial support from the Iuventus Plus Program (No. IP2014 029473).

\section{References}

[1] Willey R., Practical production of thin films, Vol. 1, Willey Optical, Consultants, Charleviox, 2008.

[2] Yang Y.-C., Chang C.-T., Hsiao Y.-C., LeE J.-W., Lou B.-S., Surf. Coat. Tech., 259 (2014), 219.

[3] Lin J., Moore J.J., Sproul W.D., Mishra B., Wua Z., WANG J., Surf. Coat. Tech., 204 (2010), 2230.

[4] Hsiao Y.-C., LeE J.-W., Yang Y.-C., Lou B.-S., Thin Solid Films, 549 (2013), 281.

[5] KaCZMareK D., DomaradzKi J., WojcieszaK D., Prociow E., Mazur M., Placido F., Lapp S., $J$. Nano Res.-Sw., 18 - 19 (2012), 195.

[6] Mazur M., SieradzKa K., KaCZMareK D., DoMARADZKI J., WOJCIESZAK D., DOMANOWSKI P., Prociow E., Mater. Sci.-Poland, 31 (3) (2013), 434.

[7] Domaradzki J., Kaczmarek D., Prociow E.L., BORKOWSKa A., SCHMEISSER D., BEUCKERT G., Thin Solid Films, $513(1-2)$ 2006, 269.

[8] Kaczmarek D., Prociow E.L., DomaradzKi J., Borkowska A., MielcareK W., WoJCIESZaK D., Mater. Sci.-Poland, 26 (1) (2008), 113.

[9] Pamu D., Ghanashyam M., Raju K.C., BhatnaGAR A.K., Solid State Commun., 135 (1 - 2) (2005), 7.

[10] Gao F.M., Gao L.H., J. Superhard Mater+, 32 (3) (2010), 148.

[11] Kulikovsky V., Ctvrtlik R., Vorlicek V., Filip J., Bohac P., JastrabiK L., Thin Solid Films, 542 (2013), 91.
[12] Löbl P., Huppertz M., Mergel D., Thin Solid Films, 251 (1994), 72.

[13] Modes T., Scheffel B., Metzner C., Zywitzki O., Reinhold T.E., Surf. Coat. Tech., 200 (2005), 306.

[14] Okimura K., Shibata A., Maeda N., Tachibana K., Noguchi Y., Tsuchida K., Jpn. J. Appl. Phys., 43 (1995) 4950.

[15] Gu G.-R., LI Y.-A., TAO Y.-C., He Z., Li J.-J., YIN H., LI W.-Q., ZHAO Y.-N., Vacuum, 71 (2003), 487.

[16] Zeman P., Takabayashi S., Surf. Coat. Tech., 153 (2002), 93.

[17] Jouanny I., Labdi S., Aubert P., Buscema C., MaciejaK O., Berger M.-H., Guipont V., JeANDIN M., Thin Solid Films, 518 (2010), 3212.

[18] Zywitzki O., Modes T., SAHM H., Frach P., Goedicke K., Glöss D., Surf. Coat. Tech., 180 - 181 (2004), 538

[19] Konstantinidis S., Dauchot J.P., HecQ M., Thin Solid Films, 515 (2006), 1182.

[20] Stranak V., QuaAs M., WulfF H., Hubicka Z., Wrehde S., Tichy M., Hippler R., J. Phys. D Appl. Phys., 41 (2008), 055202.

[21] Bendavid A., Martin P.J., Takikawa H., Thin Solid Films, 360 (2000), 241.

[22] Suda Y., Kawasaki H., Ueda T., Ohshima T., Thin Solid Films, 453 - 454 (2004), 162.

[23] Chuang L.-C., Luo C.-H., Yang S., Appl. Surf. Sci., 258 (2011), 297.

[24] Duyar O., Placido F., Durusoy H.Z., J. Phys. D Appl. Phys., 41 (2008), 095307.

[25] Gao F., Phys. Rev. B, 73 (2006), 132104.

[26] Liang Y., Zhang B., Zhao J., Phys. Rev. B, 77 (2008), 094126.

[27] Mayo M.J., Siegel R.W., Narayanasamy A., NiX W.D., J. Mater. Res., 5 (5) (1990), 1073.

[28] Schmidt-Stein F., Thiemann S., Berger S., Hahn R., Schmuki P., Acta Mater, 58 (2010), 6317.

[29] Jung H., Park C., Lee J., ParkY. S., Mater. Res. Bull., 58 (2014), 44.

[30] Jimenez Pique E., Gonzalez-Garcia L., Rico V.J., Gonzalez-Elipe A.R., Thin Solid Films, 550 (2014), 444. 
[31] Wu K.-R., TING C.-H., WANG J.-J., LiU W.-C., LIN C.-H., Surf. Coat. Tech., 200 (2006), 6030.

[32] Krishna D.S.R., Sun Y., CHEn Z., Thin Solid Films, 519 (2011), 4860.

[33] Domaradzki J., KaczmareK D., Adamiak B., Dora J., Maguda S., Polish Patent Application, P 395 346, 2011.

[34] Klug H.P., AleXander L.E., X-ray Diffraction Procedures for Polycrystalline and Amorphous Materials, $2^{\text {nd }}$ edition, John Wiley and Sons, New York, 1974.

[35] Oliver W.C., Pharr G.M., J. Mater. Res., 7 (1992), 1564.

[36] Oliver W.C., Pharr G.M., J. Mater. Res., 10 (2004), 3.

[37] FISCHER-CRIPPS A.C., Nanoindentation, Mechanical Engineering Series, Springer-Verlag, New York, 2002.
[38] Jung Y.G., Lawn B.R., Martyniuk M., Huang H., Hu X.Z., J. Mater. Res., 19 (2004), 3076.

[39] Roy S., Int. J. Fracture, 144 (2007), 21.

[40] Karimpour M., Comp. Mater. Sci., 68 (2013), 384.

[41] Kataria S., Thin Solid Films, 522 (2012), 297.

[42] Powder Diffraction File, Joint Committee on Powder Diffraction Standards, Philadelphia, PA: ASTM; 1967 Card 21-1272.

[43] Powder Diffraction File. Joint Committee on Powder Diffraction Standards. Philadelphia, PA: ASTM; 1967 Card 21-1276.

Received 2015-03-09

Accepted 2015-05-20 